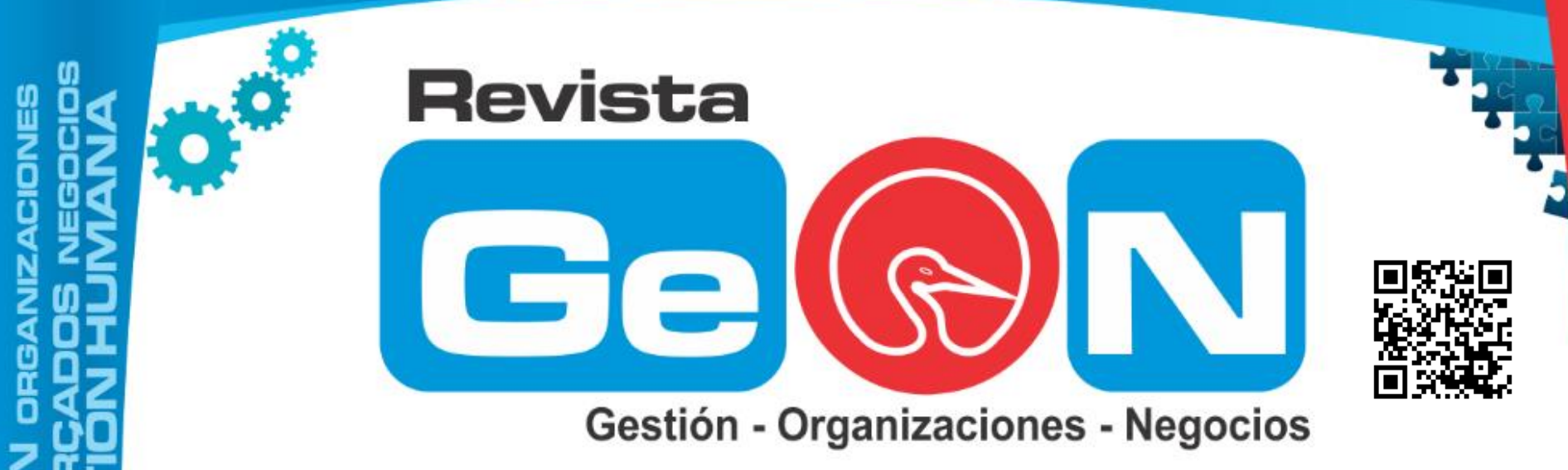

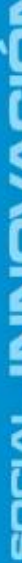

(1)

ISEN 204E - 3970

Volumen 11 Número 0 Diciembre Jullo 14

Revista Electrónica de la Facultad de Ciencias Económicas de la Universidad de los Llanos

$4 \leq 1$

$3<$

$2 \frac{1}{2} \frac{1}{4}$
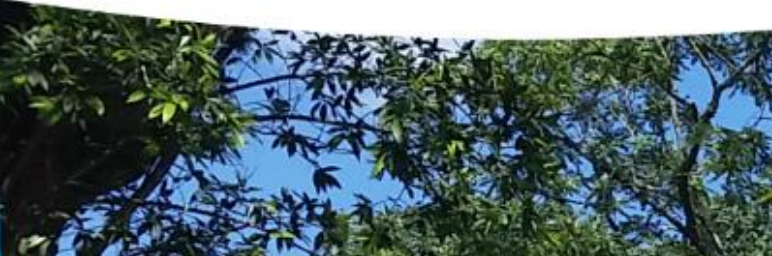

(1)

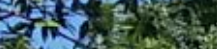

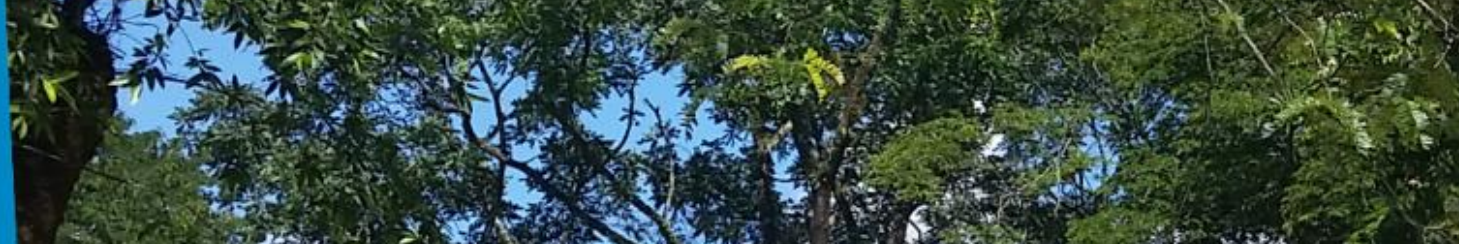

다

(11) को

$2 \frac{1}{0}$

i c

iii $\frac{2}{11}$ if

in

402

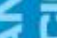

40

20 III

iㅣㄴ

12

10

10

ii 1

U1

$2 \frac{1}{2}$

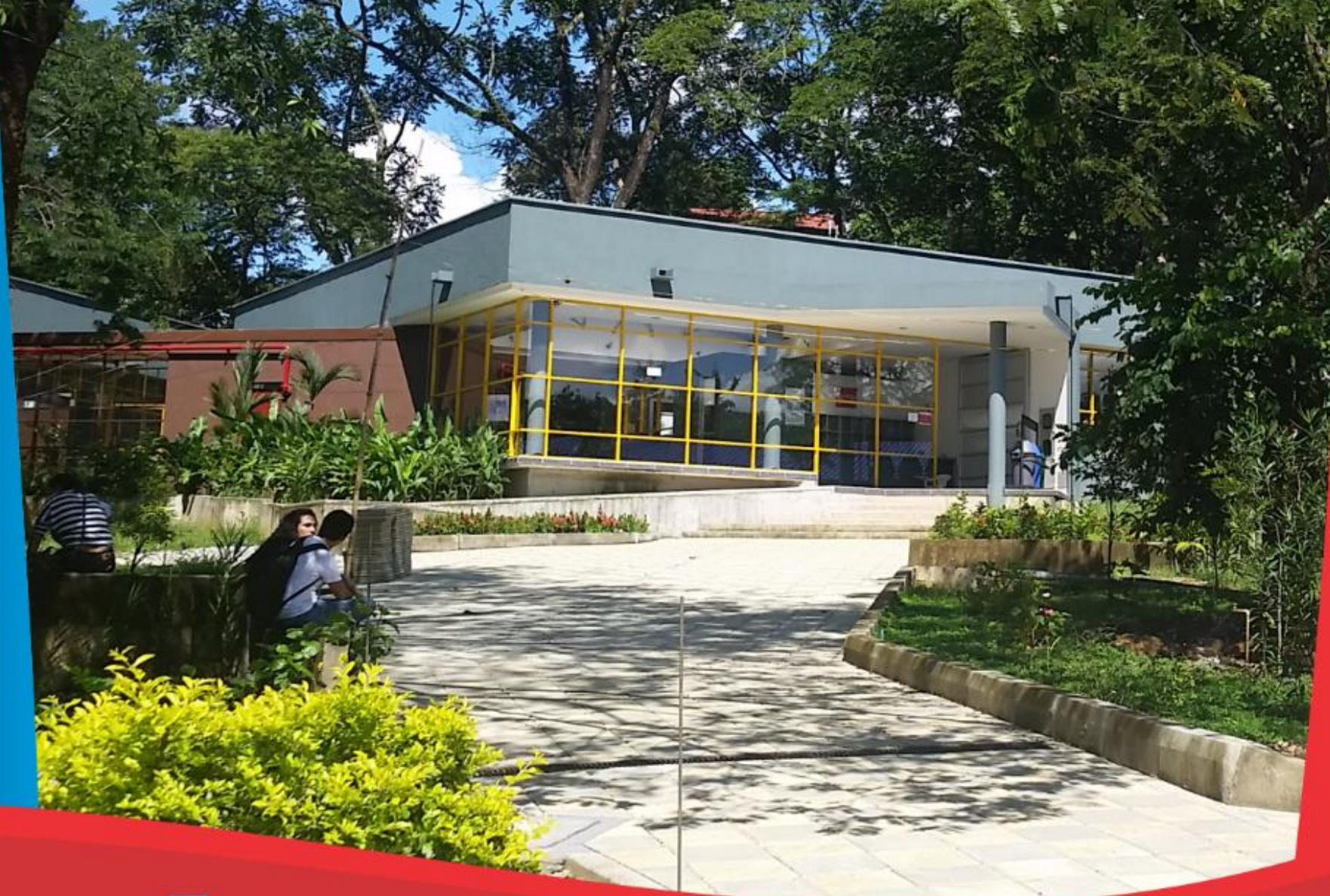

I/revistaGEON @RevistaGeon

http://revistageon.unillanos.edu.co 


\section{La Creatividad como herramienta de Liderazgo - por Vanessa Osorio}

Shirley Vanessa Osorio Parra

Economista de la Universidad de los Llanos

Especialización en Dirección de Proyectos en la

Universidad de Buenos Aires (Argentina)

(Actualmente)

@ shirleyvanessa6

\section{RESUMEN}

El presente artículo resalta la importancia de cambiar un pensamiento tradicional por una mente creativa como herramienta de gestión para direccionar una compañía, a fin de formar lideres con motivación, personas que tengan la capacidad de contextualizar las múltiples inteligencias de un equipo de trabajo e identificar las habilidades de cada uno y generar pensamientos desde un contexto crítico.

Palabras claves: liderazgo, creatividad, motivación, proyección, trabajo en equipo, habilidades.

\section{ABSTRACT}

This article highlights the importance of changing traditional thinking by a creative mind as a management tool to direct a company to train leaders with motivation, people who have the ability to contextualize the multiple intelligences of a work team and identify skills of each and generate thoughts from a critical context.

Keywords: leadership, creativity, motivation, projection, teamwork skills.

\section{INTRODUCCIÓN}

Para muchos la creatividad no tiene sentido y se preguntan ¿para qué?, pues consideran que las personas que poseen esta habilidad son personas locas fuera de contexto sin sentido de responsabilidad ni la capacidad para llevar acabo algo enserio. Por esta razón, muchas compañías solo buscan contratar personas planas sin sentido del humor que solo se dediquen a seguir los procesos rígidos. Debido a esto en el presente artículo se desglosa de forma detallada las características de un verdadero líder creativo, su importancia y el aporte significativo que este hace dentro de las organizaciones.
"Si quieres construir un barco, no empieces por buscar madera, cortar tablas o distribuir el trabajo. Evoca primero en los hombres y mujeres, el anhelo del mar libre y ancho" (Antoine de Saint Exupery).

Lo cual, expresa que cuando somos directivos de una compañía debemos en primera medida elevar las aspiraciones del equipo de trabajo, liberar sus energías y generar confianza para exponer sus ideas a fin de mejorar los resultados de la compañía. Pero más allá de esto debemos preguntarnos si un verdadero líder ¿nace o se hace?, a fin de encontrar la esencia del fundamento para ser más efectivos, y como respuesta a ello se puede decir que algunas personas nacen con ciertas características que les pueden ayudar para desenvolverse como líderes pero si estas no se desarrollan su papel como líderes será limitado, pero por lo general estas habilidades se van formando y adquiriendo en la medida que buscamos explorarlas de acuerdo a la necesidad y al entorno en el que nos movemos. Es por esto que el directivo con liderazgo es aquel que ejerce influencia sobre las personas y los incentiva para que trabajen de forma entusiasta por un objetivo común, aspecto que a diferencia del directivo tradicional se enfoca en mandar, dirigir, asignar tareas, generan temor en los empleados, asumen el papel de víctimas porque nunca se apropian de la responsabilidad de los problemas, manejan con rigurosidad y monotonía los procesos lo que ocasiona estados de estrés, baja productividad, un ambiente organizacional conflictivo, insatisfacción en el personal, productos de mala calidad y clientes insatisfechos.

Por esta razón en la actualidad se está incentivando a cambiar esa forma de dirección cuadriculada e inflexible a los cambios que la hace poco eficiente para llevar al éxito a cualquier empresa o proyecto, por uno más efectivo como el liderazgo creativo para dinamizar los procesos de las compañías, con el fin de generar un clima organizacional con mejores resultados, pero esto se logra siempre y cuando la persona desarrolle ciertas habilidades de los dos hemisferios del cerebro. Para esto se toma como referencia el modelo mental de Benziger (ver figura).

Por consiguiente el liderazgo creativo se define bajo el marco de la aplicación de las siguientes capacidades: 
1. El lenguaje verbal y no verbal. Dentro del lenguaje, un buen líder debe identificar las características de su voz para aprender a controlar el tono, la respiración y la velocidad en la que habla a fin de expresar como moderador un lenguaje verbal entendible y a su vez su lenguaje no verbal debe ser coherente con su expresión verbal, es decir que debe mantener una postura motivadora que proyecte confianza a un equipo de trabajo, lo que a su vez le permite desarrollar una buena escucha como receptor y como moderador. Con lo que se concluye que para este tipo de líder todas las opiniones, ideas y comentarios de cada uno de los miembros del equipo tienen una validez que le aportan una alternativa de solución al problema o una posible estrategia para cumplir con las metas propuestas. Porque les permite exponer y plantear con absoluta libertad sus ideas sin ser cuestionadas.

2. Creatividad, imaginación e innovación. Por medio de la creatividad el líder implementa metodologías, herramientas y técnicas que ayudan a reducir y a eliminar el poder, el ego y los protagonismos entre los miembros del equipo y fomenta una cultura de trabajo en equipo.

Por otra parte es importante mencionar que un líder estimula a dejar volar la imaginación para desarrollar ideas locas y creativas, que lleven a crear nuevos productos o servicios innovadores que revolucionen el mercado y posicionen a la empresa. A su vez, un líder creativo también se identifica porque transforma totalmente el diseño de la infraestructura de la compañía y crea espacios llenos de diseño, color, iluminación y detalles curiosos que le dan un ambiente acogedor e inspirador.

3. Análisis y determinación. El líder de un equipo en un momento dado debe tener la capacidad de orientar la conceptualización y el análisis de las ideas enmarcando unas pautas que ayuden a tomar una decisión en forma conjunta de la estrategia a desarrollar. Aunque muchas veces las acciones pueden no ser las correctas, pero es ahí donde el líder debe generar un pensamiento crítico y constructivo para ver los errores como una oportunidad para mejorar y no como algo catastrófico sin solución. Cuando se presentan situaciones de este prototipo, el líder debe motivar al miembro del equipo a encontrar la viabilidad de su propia propuesta a través del cuestionamiento de preguntas.
4. Proactividad focalizada. En este segmento una vez se ha definido la estrategia, el líder debe identificar las habilidades de cada uno de los miembros del equipo para focalizar las tareas, esto con el fin de que cada quien trabaje con apasionamiento y sea más proactivo. A demás el líder debe mostrar autoridad y una constante supervisión de las actividades, pero para ello debe usar sus herramientas de motivación, entusiasmo y aptitudes positivas para promover la disciplina y el sentimiento del logro en equipo, reconociendo siempre los esfuerzos de cada uno de los participantes.

\section{CONCLUSIONES}

En conclusión un líder creativo tiene clara y definida su visión de futuro y por esta razón pone toda su energía hacia un cambio positivo, con una actitud proactiva y optimista que lleva su profesionalismo a la cúspide del éxito, debido que tiene la capacidad de predecir y anticipar e identificar grandes oportunidades desde la simplicidad y permanece al tanto de lo que sucede en su alrededor, actuando siempre bajo un pensamiento de auto confianza, organización, planificación y estructuración sin burocratización.

Por último se puede decir que este es el modelo ideal de dirección, pero en la realidad se evidencia que es difícil aplicar todas estas características del verdadero líder porque las empresas se manejan alrededor de estos procesos cuadriculados que no dejan opciones para crear un modelo de trabajo en equipo con liderazgo, lo cual hace que la persona solo se dedique a seguir los parámetros y lineamientos estipulados.

\section{BIBLIOGRAFÍA}

Echavarría. Rafael. Escritos sobre aprendizaje. Modulo, La Escucha.

Dibrin. Andrew J.Relaciones Humanas, comportamiento humano en el trabajo. Novena Edición, 2008.

Lundin, Stephen C. Harry Paul. Christensen Jhon. Fish, La eficacia de un equipo radica en su capacidad de motivación.

Covey Stephen R. El liderazgo centrado en principios. 